\title{
Examining K-12 Teachers' Digital Competency and Technology Self-Efficacy During COVID-19 Pandemic
}

\author{
Justina A. Ogodo \\ Baylor University \\ Marsha Simon \\ University of West Georgia \\ Dana Morris \\ Baylor University \\ Mark Akubo \\ Florida State University
}

\begin{abstract}
This study used an online survey to collect data from $K-12$ teachers $(N=109)$ across twelve states in the U.S. The goal was to examine teachers' experiences, digital competency, and instructional technology selfefficacy as they transitioned from in-person to virtual learning environments. We found that a) many teachers had the digital competency for classroom instruction, they could not engage effectively with their students due to inadequate training for online instruction and limited digital tools and resources, b) teachers' level of digital competency corresponded with their self-efficacy, and c) the COVID-19 Pandemic further exposed the existing digital divide and inequitable distribution of resources.
\end{abstract}

Keywords: COVID-19, digital competency, $k$-12 education, instructional technology, teacher self-efficacy

\section{INTRODUCTION}

Over the last two decades, there has been an intentional move toward technology-supported instruction in U.S. schools, resulting in various remote educational models and approaches. This innovative form of education heralded a viable school reform mechanism encompassing different programs and operational modalities (Lane et al., 2019; Mao et al., 2019). These modalities, commonly called distance education, have progressively become an acceptable mode of instruction. According to Read et al. (2013), these forms of out-of-classroom education, online learning, virtual learning, computer, web-based, etc., involve preplanning and a well-structured form of teaching and learning. However, despite the optimistic outlook of technology-based education and its increasing use, remote education has encountered multiple challenges arising from curriculum design, policy conflicts, and an existing digital divide that separates learning in different socioeconomic contexts (Resta et al., 2018). These factors prevent a seamless integration or implementation of technology in the classroom (Mao et al., 2019). 
Moreover, the sudden shift of K-12 education to virtual spaces due to the COVID-19 Pandemic added to the existing challenges. For example, Gerber (2020) reported that many school districts were unprepared to transition from in-person to virtual education. Likewise, the United Nations Educational, Scientific, and Cultural Organization ([UNESCO], 2020) noted that teachers lacked instructional technology knowledge or digital skills during the transition. There was also the challenge of unequal access to and use of technology tools in learning contexts. These factors inhibit the successful integration of technology in K12 classrooms. More than ever, teachers needed the knowledge and skills to utilize or integrate technology during the emergency shift. Based on this knowledge, we examined K-12 teachers' experiences, digital competency, and instructional technology self-efficacy as they transitioned from in-person to virtual learning environments. We also used the term virtual and remote interchangeably to describe the teaching during the COVID-19 Pandemic outside the in-person classroom.

\section{LITERATURE REVIEW}

\section{K-12 Online Instruction Before COVID-19}

According to a recent report National Center for Education Statistics ([NCES], 2019), over 4.5 million students were enrolled in part-time and full-time online education before the COVID-19 Pandemic. However, only about $23 \%$ of courses or curricula were in an online mode. Despite the increasing online enrollment in K-12 public schools, Lynch (2020) observed the absence of a single school with $100 \%$ of its classes entirely online. Still, many innovative school districts emphasize teacher instructional technology knowledge or expertise, which many lacked because few universities prepared them for online instruction (García \& Weis, 2020; Lane et al., 2019; Mao et al., 2019). Studies indicate that the exponential growth of virtual or remote education and the enthusiasm toward a technology-based K-12 experience notwithstanding, there is an insufficient body of evidence supporting its effectiveness (Farmer \& West, 2019; Harris-Packer \& Ségol, 2015; Lane et al., 2019).

\section{Impact of the COVID-19 Pandemic on Education}

\section{Global Pandemic Impact}

Global reports reveal that the COVID-19 Pandemic had severe impacts on international education. For example, in the United Kingdom, Engzell et al. (2020) noted that students' scores on standardized tests fell at 3.13 percentile points and 0.08 standard deviations in 2020 compared to the three previous years. In Ireland, Mohan et al.'s (2020) study indicated that school shutdowns negatively impacted most schools. In Nigeria, Obiakor and Adeniran (2020) observed the digital divide between different socioeconomic groups affected many learners as most did not have the technological resources to function. Similarly, in the U.S., Kuhfield et al. (2020) projected that students would return in the 2020 fall semester with $63-68 \%$ of the previous years' learning gains in reading and $37-50 \%$ in math. Other studies anticipate a possible loss of a semester or entire year's learning (Azevedo et al., 2020; Darling- Hammond, 2020; Dorn et al., 2020). Thus, this global crisis disrupted education and would widen the existing learning gaps of many students.

\section{Impact of COVID in America}

The COVID-19 Pandemic undoubtedly placed severe restraints on students' academic progress in K12 settings in America (Cottingham et al., 2020; Dorn et al., 2020). School districts were underprepared for the emergency transition resulting in unstructured formats that may have contributed to learning loss (Azevedo et al., 2020; Darling-Hammond \& Hyler, 2020; Malkus et al., 2020). In addition, teachers and students were thrust into an unfamiliar learning environment with unreliable communication. In some cases, inconsistent directives from school administration, which may have created some learning loss. According to Dorn et al. (2020), students learning loss could occur in one of three ways those who a) progress at a slower rate in the remote environment than they would have in the in-person classroom environment despite receiving average quality instruction, b) did not progress beyond their current grade level due to the limited quality of teaching received, and or, c) did not receive any instruction at all for 
multiple reasons. While Dorn et al.'s (2020) study focused on high school settings, Engzell et al.'s (2020) investigation found similar elementary and middle grades trends.

Furthermore, the learning loss could have also resulted in the unavoidable dependence on technology. Azevedo et al. (2020) observed that digital learning best serves the learner in a supplementary role and not a replacement for face-to-face classroom instruction. The lack of preparation, family economic loss, existing inequities in technology resources, and the academic achievement gap may have contributed to the learning loss.

\section{Academic Achievement Gap in America}

Although educational gaps existed pre-pandemic, the situation worsened during the current global crisis as students, parents, and educators struggled to meet educational goals in the new instructional era (Cottingham et al., 2020; Engzell et al., 2020). The observed gaps directly impacted students from low socioeconomic status (SES) because of the lack or limited access to online learning resources coupled with less supportive or knowledgeable parents. The U.S. Census Bureau (2018) reported pre-COVID-19, a separating achievement gap between low-income minority students from middle and high-income peers. During the pandemic, Curriculum Associates (2020) observed that compared to learners in affluent school districts who accessed online instruction $90 \%$ of the time, low-income students logged in only about $60 \%$. Some students took up jobs to support their family's income due to parents' loss of employment or reduced household earning capacity (Dorn et al., 2020). As a result, students from less-educated homes are likely to suffer learning loss 55\% times more than students from educated households (Engzell et al., 2020). Saddled with life challenges, many of these students may not finish high school and attend college. Hence, complicating what Ladson-Billings (2006) called the "educational debt," a perpetuated systemic problem based on the historical, economic, sociopolitical, and moral debt owed to many underserved students.

\section{Effectiveness of Digital Learning}

Research suggests insufficient evidence of the effectiveness of digital learning (Farmer \& West, 2019; Harris-Packer \& Ségol, 2015). According to Lane et al. (2019), the measure of effectiveness is flawed because the skills needed for remote education are not equivalent to those required for face-to-face; therefore, good face-to-face teachers are not necessarily good online teachers. In their meta-analysis of 356 journal articles of K-12 online scholarship, Hu et al. (2019) observed a growing concern about the lack of research into best practices. Rehn et al. (2018) believed that the lack of online teaching expertise is attributable to the inconsistent online education standards. Teachers are often left to trial and error without guidance toward best practices until they find strategies that work for their virtual learning classrooms. Given the limited evidence of online education's effectiveness and the absence of unified online pedagogy standards, the question arises about the specific skills $\mathrm{K}-12$ teachers need to create practical lessons for learners (Rehn et al., 2018).

\section{Teacher Instructional Technology Skill}

Online teaching demands that teachers perform the pedagogical role of designing and directing the instruction, facilitating discussion, providing feedback, and navigating learner engagement. Unfortunately, many teachers lack these skills. According to Farmer and West (2019), this deficiency is due to inadequate teacher preparation that leaves several teachers grappling with online education and creates a disparity between online and in-class instruction. Studies acknowledge the need for teachers to have the competency to design well-planned online instruction and utilize practical, engaging instructional strategies (Lane et al., 2019). Without this instructional technology competency, teachers would fumble around and experiment with different approaches to do online instruction (Gross \& Opelika, 2020; Rehn et al., 2018). Unfortunately, many K-12 teachers lacked digital competency or online teaching abilities as they transitioned to virtual education. Hodges et al. (2020) noted that teachers who lack online mastery of the complex and distinctive combination of technical, pedagogical, and interpersonal skills necessary for building relationships might also deny students the educational experience that in-school education provides. 


\section{Districts' Preparedness During the Transition}

According to Gerber (2020), many school districts were unprepared for the emergency transition to the virtual learning environment. Their study of large school districts across America found that 41 of these districts, representing $85 \%$ of the sample, had no existing plan for teachers' work expectations during the pandemic (See Figure 1).

\section{FIGURE 1 \\ SCHOOL DISTRICTS PREPARATION PRE-COVID-19}

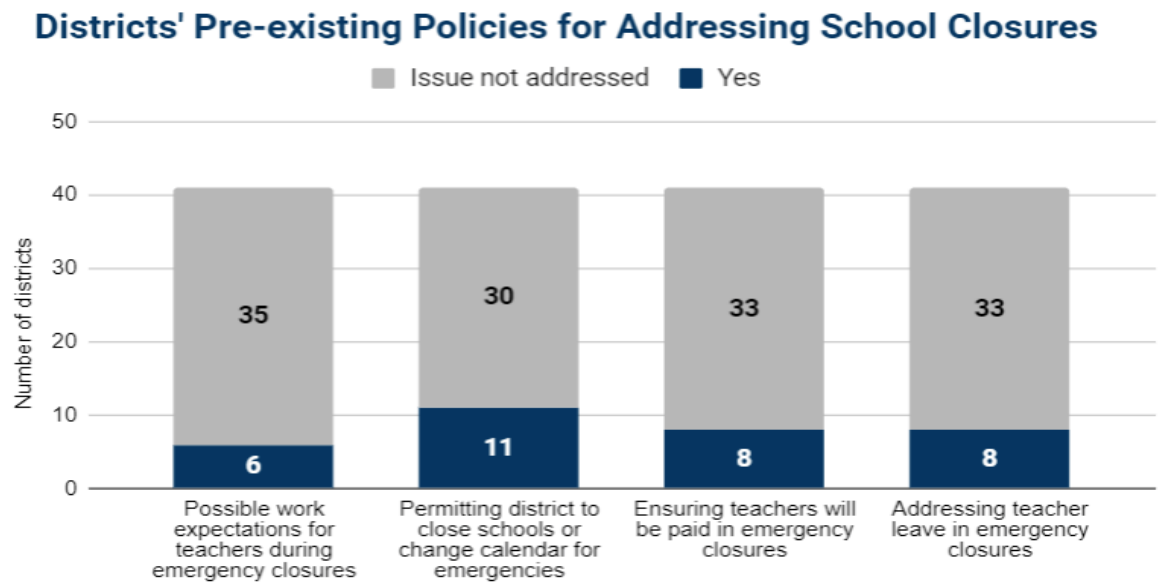

Figure retrieved from National Council for Teacher Quality (2020).

The report also noted that some school districts provided limited work structures or used Ad hoc professional development to introduce teachers to new educational platforms for instruction. Caglayan et al. (2016) also found that only about $42 \%$ of districts provided teacher professional development (PD) to increase their "familiarity" on how to use digital platforms, and $45 \%$ provided PD on how to teach in a distance learning environment. It means many school districts left teachers grappling on their own (see Figure 2).

FIGURE 2

SCHOOL DISTRICTS' EXPECTATION OF TEACHERS DURING COVID-19 REMOTE TEACHING

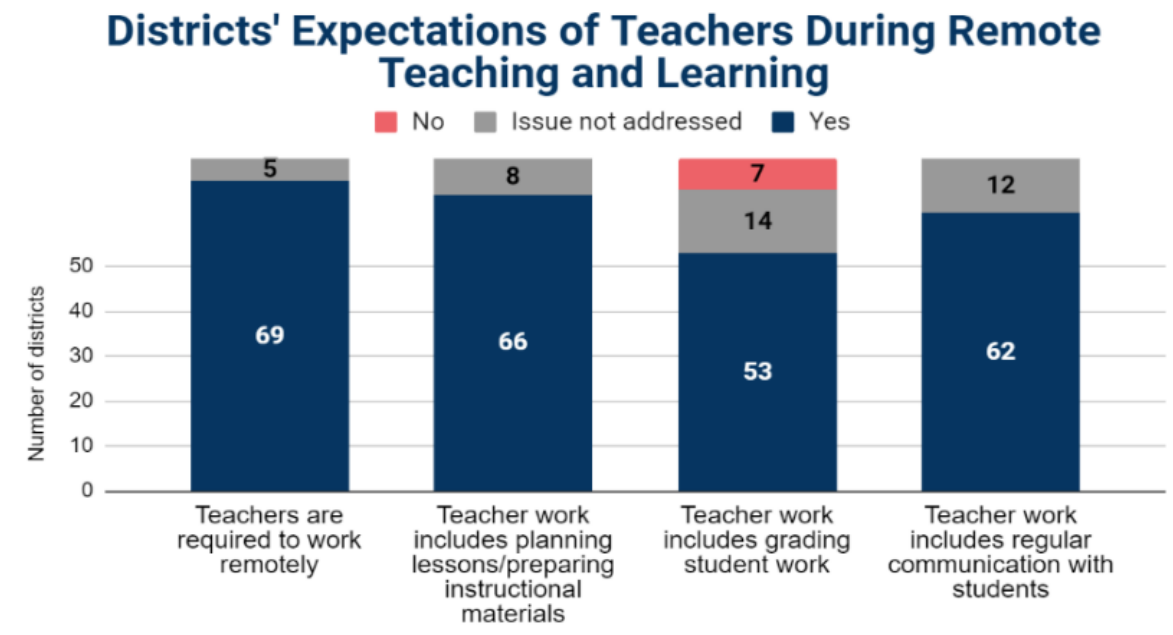

Figure retrieved from National Council for Teacher Quality (2020). 
Other studies noted that compared to suburban areas where teachers provided real-time education (Gross \& Opalka, 2020), districts in low-income rural and small-town communities did not communicate expectations on how teachers should provide instruction. Therefore, teachers used various methods to reach their students, evidence of unequal access to learning opportunities (Anderson, 2020; Blagg, Blom, Gallagher, \& Rainer, 2020; Gross \& Opalka, 2020; Hamilton et al., 2020).

\section{Planning/Instructional Methods}

Regardless of their inadequate training for online teaching, some reported little to no district or administrative support. Expectations placed on teachers increased during this transition. According to Gerber's (2020) report, teachers were tasked with re-creating instructional material, designing engaging lessons and activities, or researching new teaching methods suitable for online education. The United Nations (2020) noted that teachers were required to implement learning modalities without sufficient preparation, guidance, or resources. It is daunting for teachers to plan quality lessons with inadequate training during the emergency shift because they had to adapt to the new learning modalities while learning simultaneously (Hodges et al., 2020).

\section{Instructional Delivery}

Teacher preparation for remote education or lack thereof, and the infrastructural limitations such as access to internet connectivity, lack of digital devices - computers, iPad/Chromebooks, and Learning Management System (LMS) made the transition from in-person to virtual teaching more problematic. These associated factors led school districts to adopt varied instructional approaches during this period. According to Gerber (2020), many schools used different hybrid modalities, synchronous and asynchronous, alternating half-or full-day student schedules. Schools in suburban districts with existing 1:1 technology transitioned more seamlessly than many schools in low SES urban and rural districts where home technology and internet services were not readily available. These schools resulted in packaging hardcopy instructional material for their students/parents to pick and drop off. This instructional delivery process approach added lag time when packages were not picked up, completed, or promptly returned. The pandemic exposed the continued disparities in access to digital devices and the internet (Anderson, 2020; Darling-Hammond, 2020; Darling-Hammond \& Kini, 2020).

\section{Online Presence}

In addition to developing instructional materials to fit the new online teaching mode (Gerber, 2020), many school districts also required that teachers maintain an online presence of 45 to 60 minutes of class time and regular communication with students and their parents. Therefore, teachers used voice calls, emails, chats, text messages, and other social media outlets to communicate and provide feedback. In addition, they were expected to monitor students' daily logins, encourage them to complete tasks, etc., while managing their personal and family lives also disrupted by the pandemic.

\section{THEORETICAL FRAMEWORK}

We situated this study within Moore's $(1997,2007)$ transactional distance and Bandura's $(1994,1977)$ self-efficacy theories. The shift to a remote learning environment heightened the need to understand the expectations for learning in distance educational spaces and the need for teacher-specific competence $(\mathrm{Hu}$ et al., 2019). We used these two theoretical frameworks to examine K-12 teachers' experiences, digital competency, and self-efficacy in instructional technology.

\section{Transactional Distance Theory (TDT)}

According to Moore's (1993) transactional distance theory, the separation between teachers and students in a distance education space and the learning outcome can be shaped by three interacting characteristics, structure, dialogue, and learner autonomy. First, Moore (1993) more defined distance education as "the universe of teacher-learner relationships that exist when learners and instructors are 
separated by space and or by the time" (p. 22). Moore elucidates that there must be structured instructional strategies to bridge the interactional gap of time and space between teachers and learners in the distance education space. The structure is the nature, design, level of flexibility, or rigidity of the course and its response to the learner's need. Bair and Stafford (2016) surmised that for a teacher to be effective in an online learning environment, their instruction must be well-designed and digitally balanced. The teacher must possess the competency to develop and design lessons that support each learner in a virtual learning space. The second component of the framework is that there must be effective dialogue; instructor-learner communication. Studies support that a meaningful and engaging teacher-student dialogue is crucial to a positive, online learning outcome (Faloon, 2011; Garrison, 2016). Lastly is learner autonomy, selfdirectedness, or self-reliance of learners in managing and controlling their learning. Moore (2007) noted that the three variables are related inversely as the course structure and dialogue impact learner autonomy. A course lacking structural flexibility can decrease learner autonomy, and the quality of the dialogue between instructor and learners can increase the transactional distance between teacher and students. Conversely, when a course lacks structure, the transactional distance increases. During the emergency transition, most classes lost their structure, while some lost both structure and dialogue.

\section{Teacher Self-Efficacy}

We used Bandura's (1977) self-efficacy theory to understand the teachers' perceptions or selfconfidence vis-à-vis their technology knowledge and digital competency as they transitioned to virtual education. Self-efficacy, according to Bandura (1977), is the "beliefs in one's own capabilities to organize and execute the courses of action required to produce given attainments" (p. 3). Thus, self-efficacy is the capability exhibited as competencies and skills that enable a teacher to act professionally. Examining elementary teachers' technology integration in the classroom, Menon et al. (2017) observed that teachers' self-beliefs in their capabilities to incorporate instructional technology enabled them to promote student learning. Teachers need self-confidence in their abilities to bring about specific professional actions and practices. Research shows that if teachers perceive themselves as poor practitioners or cannot provide specific learning opportunities for their students, they will have less successful outcomes (Bandura, 1977; Hatlevik \& Christophersen, 2013; Krumsvik, 2011). Therefore, teachers' perception of themselves as they transitioned to the virtual education settings was crucial to the expected learning outcome.

\section{Digital Competency}

We describe digital competency as the instructional technology skills teachers should possess to implement classroom instruction effectively. Ally (2019) defined digital competency as the personal and pedagogical skills necessary to communicate and facilitate learning in a digital environment and outlined them as a) use of technology in general, b) development of digital learning resources, c) remixing learning resources, d) communicating and facilitating learning in a digital environment, and e) the personal and pedagogical skills necessary for these processes to occur. The 21 st-century classroom needs teachers who have more than content knowledge and pedagogical skills but the digital competence to utilize tools and resources that enhance learning. Research supports that teacher digital expertise is pivotal to teaching and learning and allows them to deliver their content using tools that support students' learning (Moore-Adams et al., 2016; Mitra, 2014). However, Anderson (2008) warns that "online learning can present challenges to educators because the tools and opportunities for discovering students' preconceptions and cultural perspectives are often limited by bandwidth constraints that limit the view of body language and paralinguistic clues" (p. 35). Therefore, the initial step to providing meaningful learning experiences in a virtual environment is the availability of digital tools for the teacher and learners. It provides the bridge for the teacher to respond to learners' needs effectively. Unfortunately, during the transition to virtual education, many K-12 teachers may have lacked digital competency.

Digital Competency and Self-Efficacy

Digital competency enables teachers to implement structured technology-based teaching and learning (Hatlevik \& Christophersen, 2013). On the contrary, the lack of technology experience or limited use in 
instructional practice could contribute to a teacher's low confidence (Anderson et al., 2011). These assertions presuppose that teachers with high technology self-efficacy can substantially integrate technology into their teaching to create learning opportunities. As many K-12 teachers stepped into the remote learning environment during the COVID pandemic, their lack of functioning digital competency may have served as a barrier and impacted their self-confidence for a successful instructional output. As the world tends towards a digital age, teacher preparedness remains an area of concern because they would be expected to use emerging technologies to enhance instruction and student learning outcomes.

\section{RESEARCH QUESTIONS}

The current pandemic thrust educators into a virtual learning environment unfamiliar to most and for which they were inadequately prepared. We used three questions to examine the experiences, digital competency, and instructional technology self-efficacy of K-12 teachers during the pandemic. First, what access to digital tools did K-12 teachers and students have at the onset of the COVID-19 Pandemic as they transitioned to a virtual learning environment? The second question addressed the teachers' technology competency and self-efficacy, "what were K-12 teachers' technology competency and self-efficacy levels as they transitioned to remote teaching during the school closings? Finally, the third question examined the challenges associated with teaching in the virtual education space, "how did K-12 teachers describe the process of remote teaching during the transition to a virtual learning environment?

\section{METHODS}

We used an online survey approach in this qualitative descriptive study (Sandelowski, 2010) to examine K-12 teachers' experiences, digital competency, and instructional technology self-efficacy as they transitioned from in-person to virtual learning environments. The online surveys allowed us to operationalize the teachers' experiences with classroom technology before and during the pandemic, their preparedness, and perceived digital competency/proficiency for remote teaching. The data collection and analysis approaches followed the traditional qualitative and quantitative methodologies to develop the research findings (Sandelowski, 2010).

\section{Data Collection}

We used a 16-item survey that was co-developed by the authors and evaluated by external survey research experts. In addition, we utilized purposeful criterion sampling to identify an initial sample of K12 teachers transitioning to the online environment and then employed snowball sampling to recruit others to participate in the study. Participation was open to all K-12 teachers online in all content areas. The openended questions generated responses from participants on their access and technology training, use of classroom technology, instructional methods, resources, and academic and administrative support received before and during the transition to remote education. Sample questions included, a) how has the current Coronavirus pandemic impacted your teaching, b) what aspect(s) of your teacher training education prepared you for virtual teaching, and c) in general, what has been the most challenging aspect of teaching and learning in a virtual environment? Unfortunately, of the 163 participants who participated in the study across twelve states in America, only 109 surveys contained complete data.

\section{Data Analysis}

The data analysis followed Sandelowski's (2014) qualitative research approach to generate information representing the participants' responses. The initial step was to open-code the raw data to extract latent words and sentences from the responses. This process involved creating groups of common words and sentences from the raw data. This process was followed by the second level of grouping or categorizing; axial coding was used to "lump" or aggregate the coded data to reduce the categories (Saldaña, 2015). During this intermediary step, we made associations and inferences between participants' responses. Lastly, we used selective coding of the categorized groups and comments to match patterns (Corbin \& Strauss, 
2015; Yin, 2018). This constant comparison of the coded data yielded the data used to make inferences to respond to the research questions. This extensive analytic process of synthesizing the data involved the coauthors engaging in multiple analytical iterations and an inter-rater comparison of the aggregated data. Finally, we calculated the prevalence rate of statements that indicated their confidence in using technology to determine teacher self-efficacy. Some examples of these statements include "I used Google classroom assignments prior to the epidemic," "I am proficient in a number of online platforms," or "I'm good with technology." If there was evidence of self-efficacy, we coded the response with " 1 ," while " 0 " coded its absence and calculated the rate of teacher self-efficacy. This process provided an aggregated data to compare the responses from the different categories developed from the qualitative research. These techniques helped us determine the extent to which the initial criterium for teaching in a remote environment was met (Moore, 1993). As a result, participants' responses offered in-depth richness to the data and a clearer picture of the teachers' experiences, digital competency, and self-efficacy.

\section{RESULTS}

The study examined K-12 teachers' experiences, digital competency, and instructional technology selfefficacy transitioning from in-person to virtual learning environments. We used the analysis result to approach the research questions from three areas developed from the data, access to digital tools, teacher digital proficiency/competency, and instructional technology self-efficacy. First, we based our findings on their interpretations of technology knowledge and the utilization of digital tools for instructions.

$\boldsymbol{R Q}_{1}$ : What access to digital tools did K-12 teachers and students have at the onset of the COVID-19 Pandemic to transition to a virtual learning environment?

\section{Teacher and Students' Access to Digital Tools}

The data indicated that only about $39.4 \%$ of teachers reported having students with complete access to digital tools needed for remote education. The other $60.6 \%$ reported that students had limited or no access to digital devices such as internet connectivity, iPads, Chromebooks, Laptops, LMS teaching tools or platforms, etc. Table 1 contains the descriptive data distribution.

TABLE 1

\section{DESCRIPTIVE ANALYSIS OF TEACHER AND STUDENT ACCESS TO DIGITAL TOOLS}

\begin{tabular}{|c|c|c|c|c|}
\hline & & & Teacher \& S & tudent Access \\
\hline & & & Frequency & Cumulative $\mathrm{P}$ \\
\hline Valid & & ited & 66 & 60.6 \\
\hline & & iplete & 43 & 39.4 \\
\hline & To & & 109 & 100.0 \\
\hline & & Teac & er \& Studen & Access \\
\hline & & & Frequency & Cumulative Percent \\
\hline & Valid & Limited & 66 & 60.6 \\
\hline & & Complete & 43 & 39.4 \\
\hline & & Total & 109 & 100.0 \\
\hline
\end{tabular}

$\boldsymbol{R Q}_{2:}$ What were K-12 teachers' digital competency and self-efficacy levels when transitioning to remote teaching during the COVID-19 school closings? 


\section{Teacher Digital Competency}

Respondents were categorized into two teacher groups, limited to basic and advanced competencies based on their self-described familiarity and proficiency with educational technology. We developed these categories by identifying words such as basic, some, limited, etc., in their responses. The groupings also included the types of technology tools they often used in their instruction, such as laptops, tablets, smartboards, PowerPoint, MSWord, Adobe, and online learning apps that included Gizmos, Kahoot, Quizlet, etc. The basic/limited teacher group made up $47.7 \%$ of the population. The other $52.3 \%$ indicated that they were proficient with the rudimentary instructional technology mentioned above but, in addition, were already using Learning Management Systems (LMS) and other blended learning approaches as part of their instructional repertoire. Some in this teacher group also have existing one-to-one access technology with their students. Table 2 presents the digital competency of participants.

TABLE 2

DESCRIPTIVE ANALYSIS OF TEACHER DIGITAL COMPETENCY

\section{Digital Competency}

\begin{tabular}{llcc}
\hline & & Frequency & Percent \\
Valid & Basic Level & 52 & 47.7 \\
& Advanced Level & 57 & 52.3 \\
& Total & 109 & 100.0 \\
\hline
\end{tabular}

Teacher Technology Self-Efficacy

We based the participants' technology efficacy on their self-reported digital competencies and comfort with instructional technology. About $64.2 \%$ reported high self-efficacy using digital devices, while the remaining 35.8\% reported low self-efficacy (see Table 3). The teachers with high self-efficacy had knowledge of basic and more complex forms of digital tools/resources like using LMSs before the pandemic. Comparatively, those who reported low self-efficacy indicated that they self-taught the new LMS introduced during the pandemic. These mainly were early career teachers between $1-5$ years who are already discovering and using tech-based resources, "I'm young enough to understand technology, so I figured it out myself mostly." Conversely, we found that those who reported low-self efficacy had a limited level of previous educational technology. Table 3 described the participants' technology self-efficacy. 
TABLE 3

DESCRIPTIVE ANALYSIS OF TEACHER TECHNOLOGY SELF-EFFICACY

\section{Teacher Technology Self-Efficacy (TTSE)}

\begin{tabular}{lccc}
\hline & Frequency & Cumulative Percent \\
Valid & Low & 39 & 35.8 \\
& High & 70 & 64.2 \\
& Total & 109 & 100.0 \\
\hline
\end{tabular}

We discovered that the higher the teacher's self-efficacy, the more digitally competent they were. In addition, the data showed that those who exhibited advanced digital competency also showed high technology self-efficacy (see Table 4).

TABLE 4

TEACHER DIGITAL COMPETENCY AND INSTRUCTIONAL TECHNOLOGY SELF-EFFICACY

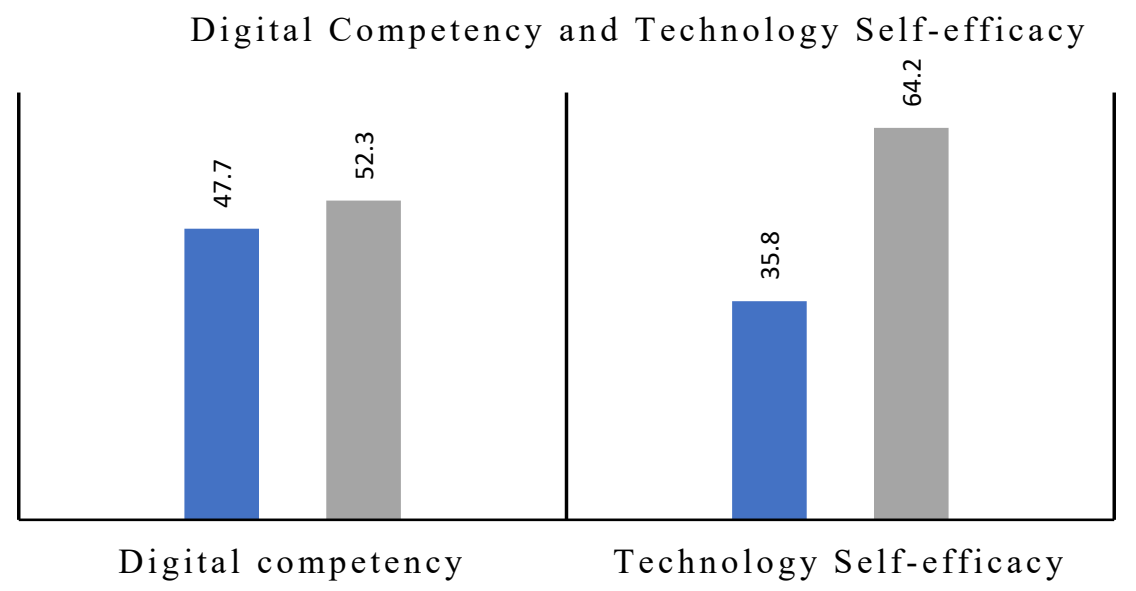

$\boldsymbol{R Q}_{3}:$ How did $K-12$ teachers describe the challenges during the transition to remote teaching during the COVID-19 school closings?

We approached this question from three perspectives, how the pandemic impacted teaching in general, the most challenging aspect of virtual education, and recommendations for the future.

\section{The Challenges of Virtual Teaching}

The findings indicated that teachers experienced three levels of challenges, a) low student participation and engagement, "we went from face-to-face to all online in a matter of about two weeks... there was a lack of student engagement and accountability despite the reduced workload," b) lack of personal interactions, reduced content and instructional time, "I am now cutting information down to bare bones, using most important facts and limited practice," "I am only able to provide new content one day a week and only about 2 hours of work per week," and "we haven't covered the depth we did in person," "without face-to-face interaction, I feel like I am not reaching all my students since I do not get to see them, and 
lastly, c) context-or subject-specific issues, "the pandemic made it difficult to reach a lot of our lowerincome students due to the lack of internet." Another teacher captured the absence of interpersonal interactions, "I am not able to reach out to all my kids. Most of my students haven't joined my google classroom, and I know there are various reasons why; some don't have access to the internet, some don't have computers."

It was also challenging for science and music teachers to conduct hands-on learning and lab activities, "we are only working on abstract ideas of music theory. We are not able to make music, which is what we do in Choir," "some don't care enough. So, my original struggle has been magnified. Luckily though, I, personally, have the technology to continue to teach; I just must find the best way to do it." These responses stress the difficulties most teachers experienced with switching to the online environment.

\section{DISCUSSION}

We examined K-12 teachers' experiences, digital competency, and technology self-efficacy during the shift from the in-person classroom to virtual learning during the COVID-19 Pandemic. Many teachers felt thrust into remote teaching without the skills or adequate preparation. In addition, most were frustrated with the process and inconsistent messages from their administrators because of school districts' lack of preparation for such a crisis (Caglayan, 2020; Gerber, 2020).

\section{Digital Competency}

The results identified two teacher groups; those who reported familiarity and or proficiency with instructional technology and those with basic or limited knowledge. About 52.3\% of the former, who selfdescribed as digitally competent, have been using advanced digital tools and applications, including LMSs, before the pandemic. In addition, most had existing tech-based programs such Apple schools, which provided a one-to-one opportunity for students, "we have been moving towards more technology in the classroom over the last few years," or "our county [district] regularly offers technology training; those have been very helpful."

In comparison, $47.7 \%$ had basic to limited digital competency. This group lacked formal academic or work-based instructional technology training and stated by one respondent, "LOL, teacher training? I had little to none." Although many in this group included veteran teachers who have more than ten years of teaching experience, "my teacher training was more theoretical than practical; it was at a time when virtual teaching was not possible." Others reported self-training or learning on the job as they taught, "I have not been prepared for virtual teaching outside of what I've implemented in my classroom on my own," and "my own effort and continual research into apps and products that are online-based... and peer interactions with like-minded goals." The findings align with a national report by Caglayan et al. (2021) that 48\% of teachers did not have an online portal before the pandemic.

\section{Self-Efficacy}

The findings showed the correlation of self-efficacy with the participants' digital competency. Hence, those who had less familiarity with instructional technology lacked digital competency and reported low technology self-efficacy. Bandura (1977) noted that individuals who believe that they do not possess the necessary skills to execute a given course of action often display a low self-efficacy to produce the expected outcome. Similarly, studies indicate that teachers who perceive themselves as insufficient in specific skills or inadequate practitioners often show low self-confidence that impacts their capacity to provide learning opportunities for their students (Author, 2019; Anderson et al., 2011; Bandura, 1994, 1977; Hatlevik \& Christophersen, 2013; Krumsvik, 2011).

Lastly, despite having digital competency, the instructional effectiveness of some teachers might have been truncated by the unavailability of digital tools and resources to their students. Moore's (1993) transactional distance theory views this lack of interface with students within the realm of lack of structural and dialogic transactions. He maintained that teachers and their students need both to function to promote 
learning. With those two elements, learner autonomy was non-existent in many classrooms during the process.

\section{CONCLUSION}

Global crises historically expose less than apparent weaknesses in any society. Unlike previous pandemics, technology played a significant role during this COVID-19 emergency. While the U.S. may be technologically advanced in many areas, it might be lagging in the education realm. Our findings indicate that multiple challenging factors contributed to teachers' instructional ineffectiveness during the transition to the virtual education world. These challenges included but were not limited to general lack of preparation by school districts, inadequate instructional technology training for teachers, and lack of access/inequitable distribution of digital tools and resources for students. The limited access to digital tools and resources restricted the instructional process, and teachers' interfaced with their students. Unfortunately, this was commonplace in low SES contexts (Gillett-Swan, 2017; Melia et al., 2019). Schools in those communities used assignment packets to provide instruction during the transition. These packages were not completed or returned most of the time. The ill-preparation for the COVID-19 emergencies also contributed to the unstructured approach across school districts and exacerbated the already widening educational gaps.

Most of the respondents believed that they were not ready for virtual education in K-12 settings, "we are not ready for online learning, we had better prepare, and we need all households to have access to WiFi." They also indicated they could not provide students with all the knowledge needed during that period. These pieces of evidence affirm other studies that showed learning loss during this period (Azevedo et al., 2020; Darling-Hammond \& Hyler, 2020).

\section{IMPLICATIONS AND RECOMMENDATIONS FOR THE FUTURE}

We documented a crucial moment in education through this investigation that implicates all stakeholders, school administrators, teachers, teacher education programs, practitioners, and educational researchers. We address these implications from three perspectives. First, what we know before the COVID-19 Pandemic, the Associated Press (2019) reported that three million students struggled to complete assignments at home due to the lack of high-speed internet access or digital tools such as laptops or desktops. The report provided actionable information for proactive steps but was not addressed. There must be educational policies and mechanisms in place to handle future crises. Such policies should encompass practical tools for teachers, students, and parents and better support for low SES families. Second, K-12 education may never return to a fully pre-pandemic approach. Given the limited evidence of online education's effectiveness, there must be specific skills for teachers and students to create effective learning. A unified approach or skill set is necessary for online pedagogy for K-12 teachers (Azevedo et al., 2020; Rehn et al., 2018). Researchers in higher education and teacher preparation programs must be on the frontline to identify the core knowledge base required for post-COVID-19 K-12 education. Third, studies indicate learning loss for learners in underserved communities (Dorn et al., 2020; Engzell et al., 2020). Remote or technology-supported education has come to stay, and beyond COVID-19 other natural disasters may disrupt schools periodically (Darling-Hammond et al., 2020; Schwartz et al., 2020). Therefore, there must be a concerted effort to bridge the existing digital divide so that all children can have access. 


\section{REFERENCES}

Anderson, A. (2020, March 10). COVID-19 Outbreak highlights critical gaps in school emergency preparedness. The Brookings Institution. Retrieved from https://www.brookings.edu/blog/education-plus-development/2020/03/11/covid-19outbreakhighlights-critical-gaps-in-school-emergency-preparedness/

Anderson, S.E., Groulx, J.G., \& Maninger, R.M. (2011). Relationships among preservice teachers' technology-related abilities, beliefs, and intentions to use technology in their future classrooms. Journal of Educational Computing Research, 45(3), 321-338.

Anderson, T. (Ed). (2008). The theory and practice of online learning (2nd ed.). Athabasca University Press.

Azevedo, J.P., Hasan, A., Goldemberg, D., Iqbal, S.A., \& Geven, K. (2020). Simulating the potential impacts of covid-19 school closures on schooling and learning outcomes: A set of global estimates. World Bank Policy Research Working Paper. https://doi.org/10.1596/1813-9450-9284

Bair, R.A., \& Stafford, T. (2016). Connected and ubiquitous: A discussion of two theories that impact future learning applications. TechTrends, 60, 129-135. https://doi.org/10.1007/s11528-016-0021$\mathrm{Z}$

Bandura, A. (1977). Self-efficacy: Toward a unifying theory of behavioral change. Psychological Review, (2), 191-215. https://doi.org/10.1037/0033-295X.84.2.191

Bandura, A. (1994). Self-efficacy. In V.S. Ramachandran (Ed.), Encyclopedia of human behavior (Vol. 4, pp. 71-81). Academic Press. (Reprinted in H. Friedman [Ed.], Encyclopedia of mental health. Academic Press, 1998). Retrieved from http://www.des.emory.edu/mfp/BanEncy.html

Bandura, A. (1997). Social learning theory. Prentice-Hall.

Blagg, K., Blom, E., Gallagher, M., \& Rainer, M. (2020). Mapping student needs during COVID-19: An assessment of remote learning environments. Washington, DC: Urban Institute. Retrieved from https://www.urban.org/research/publication/mapping-studentneeds-during-covid-19

Caglayan, K., Hodgman, S., Garet, M., \& Rickles, J. (2021). Barriers and supports teacher familiarity with digital learning tools. Retrieved from https://www.air.org/sites/default/files/Barriers-andSupports-Teacher-Familiarity-With-Digital-Learning-Tools-Feb-2021.pdf

Center on Reinventing Public Education. (2020, April 3). District Responses to COVID-19 School Closures. Retrieved from https://www.crpe.org/content/covid-19-school-closures

Christophersen, K.A., Elstad, E., Turmo, A., \& Solhaug, T. (2016). Teacher education programmes and pupil Engagement. Scandinavian Journal of Educational Research, 60(2), 240-254. https://doi.org/10.1080/00313831.2015.1024162

Cottingham, B., Gallagher, A., Gee, K., Myung, J., Gong, A., Kimner, H., . . Hough, H. (2020, July 13). Supporting Learning in the COVID-19 Context: A Summary Brief. Policy Analysis for California Education. Retrieved from https://edpolicyinca.org/publications/supporting-learning-covid-19context

Darling-Hammond, L., \& Hyler, M.E. (2020). Preparing educators for the time of COVID... and beyond. European Journal of Teacher Education, 43(4), 457-465. https://doi.org/10.1080/02619768.2020.1816961

Darling-Hammond, L., \& Kini, T. (2020, May 19). A New "New Deal” for Education: Top 10 policy moves for states in the COVID 2.0 Era. Learning Policy Institute. Retrieved from https://www.forbes.com/sites/lindadarlinghammond/2020/05/19/a-new-new-deal-for-educationtop-10-policy-moves-for-states-in-the-covid-20-era/?sh=72bad7056266

Darling-Hammond, L., Schachner, A., \& Edgerton, A.K. (2020, September 15). Reinventing School in the COVID Era and Beyond. Learning Policy Institute. Retrieved from https://learningpolicyinstitute.org/blog/covid-reinventing-school

Dorn, E., Hancock, B., Sarakatsannis J., \& Viruleg, E. (2020). COVID-19 and student learning in the United States: The hurt could last a lifetime. McKinsey \& Company. Retrieved from 
https://www.mckinsey.com/industries/public-sector/our-insights/covid-19-andstudentlearning-inthe-united-states-the-hurt-could-last-a-lifetime

Faloon, G. (2011). Making the connection: Moore's theory of transactional distance and its relevance to the use of a virtual classroom in postgraduate online teacher education. Journal of Research on Technology in Education, 43(3), 187-209. Retrieved from http://www.tandfonline.com/doi/abs/10.1080/15391523.2011.10782569

Farmer, T., \& West, R. (2019). Exploring the concerns of online k-12 teachers. Journal of Online Learning Research, 5(1), 97-118. https://www.doi.org/10.1177/0047239516637072

Garrison, R. (2016). E-learning in the 21st century: A community of inquiry framework of research. Routledge.

Gerber, N. (2020, May 28). Update on districts' teacher policy responses to COVID-19. A National Council on Teacher Quality Report. Retrieved from https://www.nctq.org/blog/Update-ondistricts-teacher-policy-responses-to-COVID--19

Gillett-Swan, J. (2017). The challenges of online learning supporting and engaging the isolated learner. Journal of Learning Design, 10(1), 20. Retrieved from http://ezproxy.acbv.talonline

Gross, B., \& Opalka, A. (2020, June). Too many schools leave learning to chance during the pandemic. Retrieved from https://www.crpe.org/publications/too-many-schools-leave-learningchanceduring-pandemic

Hamilton, L.S., Kaufman, J.H., \& Diliberti, M. (2020). Teaching and leading through a pandemic: Key findings from the American Educator Panels Spring 2020 COVID-19 Surveys. Santa Monica, CA: RAND Corporation. Retrieved from https://www.rand.org/pubs/research_reports/RRA1682.html

Harris-Packer, J.D., \& Ségol, G. (2015). An empirical evaluation of distance learning's effectiveness in the K-12 setting. American Journal of Distance Education, 29(1), 4-17. https://doi.org/10.1080/08923647.2015.990768

Hatlevik, O.E. (2016). Examining the relationship between teachers' self-efficacy, their digital competency, strategies to evaluate information, and use of ICT at school. Scandinavian Journal of Educational Research, 61(5), 555-567. https://doi.org/10.1080/00313831.2016.1172501

Hodges, C., Moore, S., Lockee, B., Tory, T., \& Bond, A. (2020, March 27). The difference between emergency remote teaching and online learning. EDUCAUSE Review. Retrieved from https://er.educause.edu/articles/2020/3/the-difference-between- emergency-remote-teaching-andonline-learning\#fn5

Hu, M., Arnesen, K., Barbour, M.K., \& Leary, H. (2019). A Newcomer's Lens: A Look at K12 Online and Blended Learning in the Journal of Online Learning Research. Journal of Online Learning Research, 5(2), 123-144. Retrieved from https://www.learntechlib.org/primary/p/195231/

Krumsvik, R.J. (2011). Digital competence in the Norwegian teacher education and schools. Heogre Utbildning, 1(1), 39-51.

Krumsvik, R.J. (2014). Teacher educators' digital competence. Scandinavian Journal of Educational Research, 58(3), 269-280. http://dx.doi.org/10.1080/00313831.2012.726273

Lane, H., Richard, H., \& Richard, T. (2019). Handbook of research on emerging practices and methods for $k-12$ online and blended learning. IGI Global.

Lynch, M. (2020). E-Learning during a global pandemic. Asian Journal of Distance Education, 15(1), 189-195. https://doi.org/10.5281/zenodo.3881785

Malkus, N., Christensen, C., \& Schurz, J. (2020). School district responses to the COVID-19 Pandemic: Round 6, ending the year of school closures. American Enterprise Institute. Retrieved from https://www.aei.org/research-products/report/schooldistrict-responses-to-the-covid-19-pandemicround-6-ending-the-year-of-school-closures/

Mao, J., Ifenthaler, D., Fujimoto, T., Garavaglia, A., \& Rossi, P.G. (2019). National policies and educational technology: A synopsis of trends and perspectives from five countries. Tech Trends, 63(3), 284-293. https://doi.org/10.1007/s11528-019-00396-0 
Menon, D., Chandrasekhar, M., Kosztin, D., \& Steinhoff, D. (2017). Examining preservice elementary teachers' technology self-Eeficacy: Impact of mobile technology-based physics curriculum. Contemporary Issues in Technology and Teacher Education, 17(3), 336-359. https://www.learntechlib.org/primary/p/178190/

Mitra, S. (2014). The future of schooling: Children and learning at the edge of chaos. Prospects, 44, 547558. https://www.doi.org/10.1007/s11125-014-9327-9

Mohan, G., McCoy, S., Carroll, E., Mihut, G., Lyons, S., \& Domhnaill, C.M. (2020). Learning for all? Second-level education in Ireland during COVID-19. Esri Survey and Statistical Report Series, 92.

Moore, M. (1993). Theory of transactional distance. In D. Keegan (Ed.), Theoretical principles of distance education (pp. 22-38). Routledge.

Moore, M.G. (2007). The theory of transactional distance. In M.G. Moore (Ed.), Handbook of distance education (pp. 89-105). Lawrence Erlbaum Associates.

Moore-Adams, B.L., Jones, W.M., \& Cohen, J. (2016). Learning to teach online: A systematic review of the literature on K-12 teacher preparation for teaching online. Distance Education, 37(3), 333348. https://doi:10.1080/01587919.2016.1232158

NCES. (2019). Postsecondary Outcomes for Nontraditional Undergraduate Students. Retrieved from https://nces.ed.gov/programs/coe/indicator_tta.asp

Obiakor, T., \& Adeniran, A. (2020). COVID-19: Risk-control measures threaten to deepen Nigeria's education crisis. Centre for the Study of Economies of Africa (CSEA). Retrieved from $\mathrm{http}$ //cseaafrica.org/covid-19-risk-control-measures-threatens-to-deepen-nigerias-educationcrisis/

Read, D., Coles, S., Frey, J., \& Littlefield, B. (2013). Investigating the use of virtual Learning Environments by teachers in schools and colleges. Retrieved from http://eprints.soton.ac.uk/342377/1/DRead_VLE_report.pdf

Rehn, N., Maor, D., \& McConney, A. (2018). The specific skills required of teachers who deliver k-12 distance education courses by synchronous video-conference: Implications for training and professional development. Technology, Pedagogy, and Education, 27(4), 417-429. https://doi.org/10.1080/1475939X.2018.1483265

Resta P., Laferrière, T., McLaughlin, R., \& Kouraogo, A. (2018). Issues and Challenges Related to Digital Equity: An Overview. In J. Voogt, G. Knezek, R. Christensen, \& K.W. Lai (Eds.), Second Handbook of Information Technology in Primary and Secondary Education. Springer International Handbooks of Education. Springer, Cham. https://doi.org/10.1007/978-3319-538037_67-1

Sandelowski, M. (2010). What's in a name? Qualitative description revisited. Research in Nursing \& Health, 33(1), 77-84. https://doi.org/10.1002/nur.20362

Schwartz, H.L., Grant, D., Diliberti, M.K., Hunter, G.P., \& Setodji, C.M. (2020). Remote Learning Is Here to Stay: Results from the First American School District Panel Survey. Creative Commons Attribution 4.0 International Public License. Retrieved from https://www.rand.org/pubs/research_reports/RRA956-1.html

UNESCO. (2020). COVID-19 Educational Disruption and Response. Retrieved from https://en.unesco.org/covid19/educationresponse

United Nations. (2020, August). Policy Brief: Education During COVID-19 and Beyond. Retrieved from https://unsdg.un.org/resources/policy-brief-education-duringcovid-19-and-beyond

United States Agency for International Development (USAID). (2014, April 4). Guide to Education in Natural Disasters: How USAID Supports Education in Crises. Retrieved from https://www.usaid.gov/what-we-do/education/educating-children-and-youth- crisis-andconflictsituations/Guide-Education-Natural-Disasters 